\title{
Incidental Asymptomatic Diaphragmatic Hernia in An Adult At Postmortem: - A Report of A Case and Literature Review
}

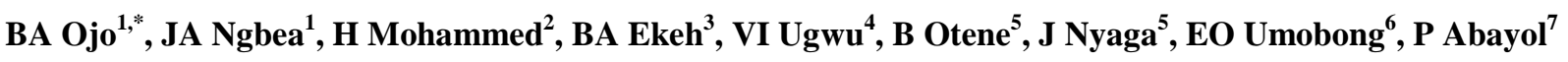 \\ ${ }^{1}$ Department of Histopathology, College of Health Sciences, Benue State University, Makurdi, Nigeria \\ ${ }^{2}$ Department of Radilology, College of Health Sciences, Benue State Universiy, Makurdi, Nigeria \\ ${ }^{3}$ Department of Surgery, College of Health Sciences, Benue State University, Makurdi, Nigeria \\ ${ }^{4}$ Department of Pathology, National Orthopedic Centre, Enugu, Nigeria \\ ${ }^{5}$ Department of Histopathology, Benue State University Teaching Hospital, Makurdi, Nigeria \\ ${ }^{6}$ Department of Laboratory Medicine, State-House Hospital, Asokoro, Abuja, Nigeria \\ ${ }^{7}$ Faculty of Clinical Science, College of Health Sciences, Benue State University, Makurdi, Nigeria \\ *Corresponding author: babarindeo87@gmail.com
}

Received August 16, 2014; Revised October 05, 2014; Accepted October 14, 2014

\begin{abstract}
Diaphragmatic hernia in the absence of trauma is very rare in adults. Congenital diaphragmatic hernia is a major malformation and a relatively common condition found in babies. We present an incidental asymptomatic diaphragmatic hernia found in a middle age man brought for medico-legal autopsy. He was brought in dead with a gunshot wound to the right anterolateral aspect of the neck. With a complex embryological story, congenital abnormalities of the diaphragm are unusual but far more common are the acquired hernia. We discuss the index case and other causes of diaphragmatic hernia.
\end{abstract}

Keywords: autopsy, diaphragm, hernia, incidental

Cite This Article: BA Ojo, JA Ngbea, H Mohammed, BA Ekeh, VI Ugwu, B Otene, J Nyaga, EO Umobong, and P Abayol. "Incidental Asymptomatic Diaphragmatic Hernia in An Adult At Postmortem: - A Report of A Case and Literature Review.” American Journal of Medical Sciences and Medicine, vol. 2, no. 5 (2014): 96-98. doi: 10.12691/ajmsm-2-5-3.

\section{Introduction}

Diaphragmatic hernia which represents a defect or hole in the diaphragm allowing the abdominal contents to move into the chest cavity, in the absence of trauma is very rare in adults (1). Congenital diaphragmatic hernia is a major malformation occasionally found in newborns and babies. It is a relatively common condition that occurs in less than one to five babies 1000 births [2] to one in 4000 live births [3,4]. It seems to be slightly more frequent in men and less frequent in blacks [5,6]. Prenatal ultrasonography demonstrates herniation of the bowel or liver into the thorax and permits prenatal diagnosis in 50\% to $90 \%$ of cases [7].

Adult onset diaphragmatic hernia is a rare condition with variable clinical manifestation [8]. The majority of adult onset diaphragmatic hernia is associated with trauma or penetrating injury $[8,9,10,11]$, with only a few reported cases not involving the type of obvious damage or injury. $[3,12]$. Blunt thoracic and abdominal trauma are associated with a $5 \%$ to $7 \%$ incidence of diaphragmatic injury and in $3 \%$ to $15 \%$ for those with penetrating injury [8]. These injuries may occur and be left unrecognized but often uncovered months later during work up for related symptoms.
In this reports, we describe the case of an incidental asymptomatic diaphragmatic hernia in a patient that presented at autopsy following a gunshot wound to the neck. Patient had no known history of trauma or a penetrating wound of the chest. Autopsy showed a through and through perforation of the presenting bowel content in the thorax cavity.

\section{Case-report}

A middle age man was found inside a street gutter lying supine by the side of a busy road. A medico-legal autopsy was requested to determine the cause and manner of death. The body measured $185 \mathrm{~cm}$ and weighed approximately $80 \mathrm{~kg}$. External examination revealed a gunshot entry wound at the right anterolateral aspect of the neck with hematoma at the right anterolateral aspect of the neck with neck dissections. No lacerations of the neck great vessels were noted. There was fractured C3-C5 vertebra. Thoracic dissection demonstrated severe and extensive laceration of upper segment of the left lung (posteriorly) with approximately 2.0 liters of hemothorax. There was a diaphragmatic hernia (Figure 1 - Figure 3) through weakened and widened esophagus hiatus. The stomach cardiac remains in its normal position with an intact 
cardio-esophageal junction, but the fundus of the stomach herniated through the hiatus. There was a through and through perforation of the herniated stomach (Figure 2) fundus with soiling of the left thoracic cavity (Figure 1) with food particles in the process of digestion. The liver looked pale with the kidneys showing evidence of shock. There was an exist wound at the level of $9^{\text {th }}-10^{\text {th }}$ ribs, left anterolateral space. Based upon the macroscopic observation, the principal cause of death was recorded as perforating gunshot wound to the neck (Rt), skeletal (C3C5) fracture, extensive left upper lung laceration with hemothorax and perforated hiatus hernia viscus (stomach fundus). The mechanism of death was hemorrhagic shock and was ruled as homicide. A retrospective review of his case-record and discussion with his family physician revealed no history suggestive of either a symptomatic hiatus hernia or past trauma to the chest.

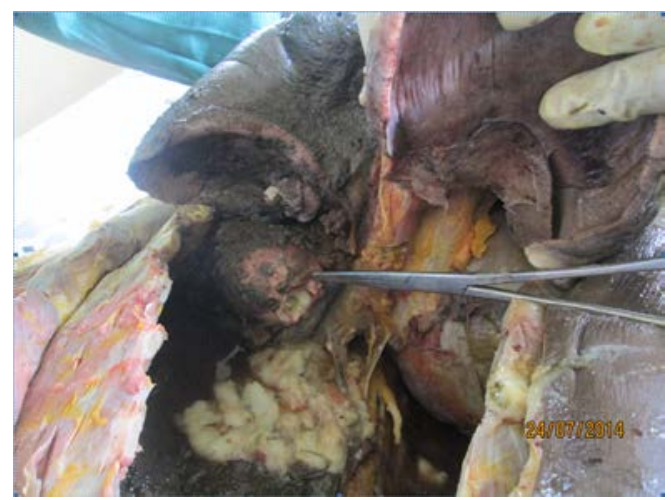

Figure 1. Soiling of the thoracic cavity by partially digested food from the perforated hiatus hernia viscus (stomach fundus)

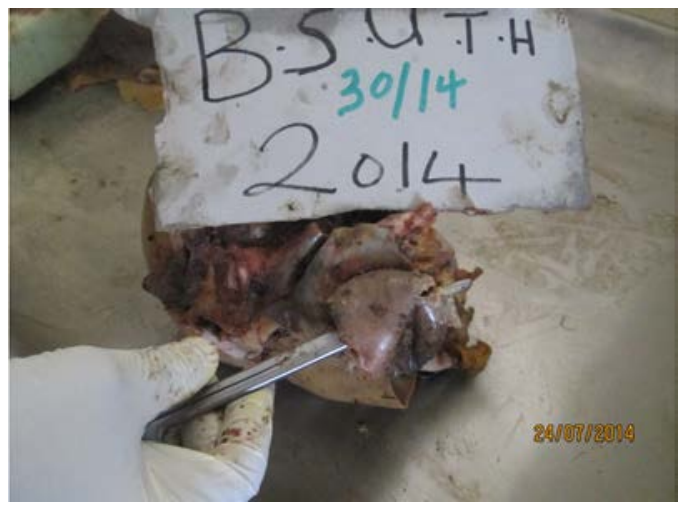

Figure 2. Through and through perforation of the herniated stomach fundus

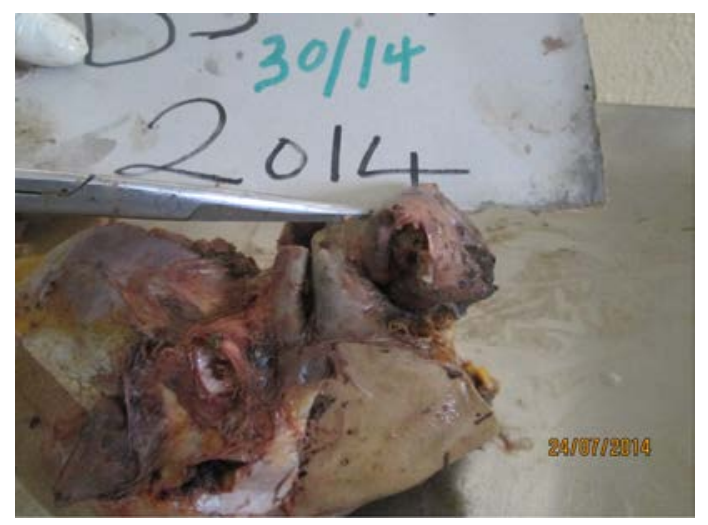

Figure 3. Herniation of the stomach fundus through the hiatus in the diaphragm. The liver is below the diaphragm

\section{Discussion}

The irony of the complex embryological story of the diaphragm is that congenital abnormalities of the diaphragm are unusual [13]. Far more common are the acquired hiatus hernia subdivided into sliding and rolling hernia.

These are found in patients usually of middle age where weakening and widening of the esophageal hiatus has occurred [13]. Our index patient was a middle age man and autopsy shows weakened and widened esophageal hiatus. The presentation is that of rolling hernia also called para-oesophageal hernia as the cardiac remains in its normal position with an intact cardio-esophageal junction with the rolling of the stomach fundus through the hiatus in front of the esophagus [13]. Our patient remained asymptomatic throughout his lifetime but para-esophageal hernia may present with epigastric discomfort, flatulence and even dysphagia.

The most frequent cause of diaphragmatic herniation of abdominal viscera in adults seems to be trauma, whereas in babies or newborns, it is most attributable to congenital absence or defective fusion of the septum transversum or the pleuroperitoneal membrane $[1,8,13]$. Acquired diaphragmatic hernias may arise from penetrating or blunt trauma, or may be iatrogenic [14]. It may present immediately after the injury or after a delay, sometimes of many years. Severe blunt trauma to the trunk is associated with diaphragmatic rupture in about $5 \%$ of cases $[15,16]$. These patients frequently have other injuries, including intracranial hematomas (25\%), fractures of the pelvis (25\%) and long bones (50\%) and injuries to intraabdominal viscera (50\%) and injuries to the heart and great vessels(10\%). Ribs fractures are not universal with a reported incidence of $47 \%$ in a large series [14,17-22]. The usual mechanism of injury is thought to be compression of the abdomen, with fracture of the diaphragm under the increased pressure but occasionally the diaphragm may be torn by direct trauma from fractured ribs [14]. In this reported case, there was no previous recorded trauma and even at autopsy no fractured rib was seen.

Congenial diaphragmatic hernia $(\mathrm{CDH})$ is an idiopathic human malformation that usually presents in the newborn period [7]. CDH represents a displacement of the abdominal organs into the thoracic cavity through a weak area or a distinct defect in the diaphragm. The most frequent types of $\mathrm{CDH}$ are the left posterolateral (Bochdalek hernia) and the sternocostal (Morgagni hernia) type. Bochdalek hernia, which result from inadequate closure of posterolateral pleuroperitoneal membrane is the most seen congenital diaphragmatic hernia [23] with majority presenting during neonatal life and have a poor prognosis, being associated with congenital pulmonary abnormalities [24,25]. In adult life, they remain largely asymptomatic and are usually incidental findings on chest radiographs or computerized tomography [26]. Foramen of Morgagni hernias are rare diaphragmatic hernias usually occurring on the right and located in the anterior mediastinum. In adults, trauma, weight lifting or other causes of increased intra-abdominal pressure.

Management of diaphragmatic hernia depend on high index of suspicion in any patient with major trauma to the trunk, especially with fractured ribs or basal shadowing on 
the chest X-ray or presence of a gas filled issues in left chest which is diagnostic [15]. In a stable patient, ultrasound or CT may provide additional useful information. When the diagnosis is confirmed, the preferred operative approach is through a laparotomy. This enables a thorough inspection of the abdominal contents $[14,22,27,28]$. For a more stable patient with delayed diagnosis, adhesions, may develop rapidly in the chest and may form within a few days of injuries, these necessitating thoracotomy as the approach of choice when diagnosis is delayed [14].

Our index patient presented at autopsy as an incident finding. Acquired hernias may present as acute surgical emergency to chronic poorly defined disorder. The surgeon should have this as one of his diagnoses especially in patient with history of major trauma to the trunk.

\section{Conclusion}

Despite the complexity of its embryology, congenital abnormalities of the diaphragm are unusual. We have presented a case of acquired hiatus, rolling hernia that was an incidental autopsy finding in a middle age asymptomatic adult. Acquired diaphragmatic hernias arising from penetrating or blunt trauma are more common. The congenital diaphragmatic hernias are probably caused by disturbed molecular signaling during organogenesis and are associated with congenital pulmonary abnormalities.

Good management which includes early detections and repair reduces mortality and morbidity.

\section{Conflicts of Interest}

The authors declare there are no conflicts of interest.

\section{Funding}

None.

\section{Acknowledgement}

The authors thank the department of Histopathology, Benue State Teaching Hospital and Madonna Hospital, Makurdi, Benue State for providing access to their records.

\section{References}

[1] Aydin Kurt, Kemal Ridvan Yazicioglu, Ali Ipek, Ozgur Tosun Mahmet Coskun. Right sided diaphragmatic hernia in an adult without history of trauma: Unusual CT findings. Eur J Gen Med 2004: 1 (3): 55-57.

[2] Gattot D, Boda C, Ughetto S, Perthus I, Robert-Gnansia E, Francannet C, Laurichesse-Delmas H, Jani J, Coste K, Deprest J, Labbe A, Sapin V, Lemery D. Prenatal detection and outcome of congenital diaphragmatic hernia: a French registry-based study. Ultrasound Obstet Gynecol 2007, 29: 276-283

[3] Kapur B, Thomas S. Adult Bochadalek Hernia-Clinical features, management and results of treatment. Japanese Journals of Surgery 1991; 21: 114-9.

[4] Gale ME. Bochadalek Hernia: Prevalence and CT characteristics. Radiology 1985; 156: 449-52.

[5] Torfs CP, Curry CJ, Bateson TF, Honore LH: A population-based study of congenital diaphragmatic hernia. Tetralogy 1992; 46: 555-565.

[6] Yang W, Carmichael SL, Harris JA, Shaw GM: Epidermiologic characteristics of congenital diaphragmatic hernia among 2.5 million California births, 1988-1997. Birth Defects Res. A Clin Mol Teratol 2006; 76: 170-174.

[7] Enrica Bianchi, Paola Mancini, Stefania De Vito, Elena Pompili, Samanta Taurone,Isabella Guerrisi, Antonino Guerrisi, Vito D' Andrea, Vito Cantisani and Marco Artico. Congenital asymptomatic diaphragmatic hernias in adults: a case series. Journal of Medical Case Reports. 2013; 7: 125.

[8] George Pei Cheung Yang, Chung Ngai Tang, Wing Tai Siu, Joe Ping Yiu Ha, Yuk Ping Tai, Michael KaWah Li. Diaphragmatic hernia: An uncommon cause of dyspepsia. JSLS. 2005 Jul-Sep: 9 (3): 352-355.

[9] Killeen KL, Mirvis SE, Shanmuganathan K. Helical CT of Diaphragmatic Rupture caused by Blunt Trauma. AJR 1999; 173: 1611-6.

[10] Kearney PA, Rouhana SW, Burnay RE. Blunt Rupture of the Diaphragmatic: Mechanism, Diagnosis, and Treatment. Annals of Emergency Medicine 1989; 18: 1326-30.

[11] Demos TC,Solomon C, Posniak HV, Flisak MJ Computed Tomography in Traumatic defects of the Diaphram. Clinical Imaging 1989; 13: 62-7.

[12] Mar Fan MJ, Coulson ML, Siu SK. Adult Incarcerated Right-sided Bochdalek Hernia. Aust NZJ Surg 1999; 69: 239-41.

[13] Harold Ellis: The diaphragm In Clinical Anatomy. $11^{\text {th }}$ Ed. Blackwell publishing UK: 2006: 14-18.

[14] Johnson, CD and Ellis, H. Acquired hernias of the diaphragm. Postgraduate Medical Journal. 1988; 64, 317-321.

[15] Waldschmidt, M.L \& Laws H.L. Injuries of the diaphragm. J Trauma 1980, 20: 587-592.

[16] Brearley, S. \& Tubbs, N. Rupture of the diaphragm in blunt injuries of the trunk. Injury 1981, 12: 480-484

[17] Williams, R.S Traumatic rupture of the diaphragm. Med J Aust 1982, 1: 208-201.

[18] McElwee, TB, Myers, R.T \& Pennell, T.C. Diaphragmatic rupture from blunt trauma. Am Sur 1984, 50: 143-149.

[19] Visset, J., Le Neel, J.C. Duveau, D, Paineau, J. \& Hingrat, J.Y. Ruptures traumatiques du diaphragm. Presse Med 1983, 12: 12111214.

[20] van der Werken, C, Lubbers, E.J.C. \& Goris, R.J.A. Rupture of the diaphragm by blunt trauma as a marker of injury severity. Injury 1984, 15: 149-152.

[21] McCune, R.P., Roda, C.P. \& Eckert, C. Rupture of the diaphragm caused by blunt trauma. J Trauma 1976, 16: 531-537.

[22] Ward, R.E., Flynn, T.C. \& Clark, W.P. Diaphragmatic disruption secondary to blunt abdominal trauma, J. Trauma 1981, 21: 35-38.

[23] Ahrend TR, Thompson BW. Hernia of the foremen of Bochadalek in the adult. Am J Surgery 1971: 122: 612-615.

[24] Nouheim K.S. Adult presentation of unusual diaphragmatic hernias. Chest Surg Clin. N Amer 1998; 8: 359-369.

[25] Wiseman NE, Macpherson RI. “Acquired” congenital diaphragmatic hernia J. Paediatr Surg 1997: 12: 657.

[26] Wilkins, AC, Govodes, GF, HibbeIn, JF. Imaging findings in adult Bochdaleck hernias. Clin Imaging 1994; 18: 224-229.

[27] Niville, EC, Himpens, JN, Bruosa, PC \& Gruwez,J A. The use of laparotomy in the treatment of recent diaphragmatic rupture due to blunt trauma. Injury 1984, 15: 153-155.

[28] Rodriguez-Morales. G., Ridriguez, A \& Shatney, CH. Acute rupture of the diaphragm in blunt trauma; analysis of 60 patients. J Trauma 1986; 26: 438-444. 